\title{
TIPOLOGIA URBANA:
}

\author{
SOBRE A DERIVAÇÃO DE UM CONCEITO \\ DA ARQUITETURA DO EDIFÍCIO PARA O URBANISMO
}

\author{
Helena Lucia Zagury Tourinho
}

\begin{abstract}
RESUMO: O artigo discute o desenvolvimento e a aplicação do conceito de tipologia na análise do espaço urbano moderno e pós-moderno. Mostra que a derivação da noção de tipologia edilicia para a análise de tipologias urbanas tem sido insuficiente para a compreensão e a classificação das cidades contemporâneas, uma vez que as reduz a conjuntos de fragmentos desarticulados no espaço. Após questionar a importância, a utilidade e a necessidade da categoria tipologia para a apreensão da forma urbana no estágio atual de desenvolvimento do capitalismo e das cidades, conclui apontando para a necessidade de repensar o conceito de tipologia urbana, de modo a resgatar a visáo de totalidade urbana e sem perder de vista as diversidades e a complexidade do espaço intraurbano atual.
\end{abstract}

PALAVRAS-CHAVE: tipologia urbana; tipologia arquitetônica; forma urbana; modernismo; pós-modernismo.

\section{INTRODUÇÃO}

$\mathrm{O}$ artigo discute o desenvolvimento e a aplicação do conceito de tipologia na análise do espaço urbano moderno e pós-moderno. Pretende fazer uma leitura sobre como o debate da tipologia da arquitetura, a partir da ótica do edifício, insere-se na perspectiva do urbanismo que trata da cidade como um todo e aponta algumas consequências que isso trouxe para o planejamento urbano. Entende o urbanismo como o pensamento e a prática sobre o espaço construído da cidade e o planejamento urbano como a atividade que visa a promover o ordenamento territorial urbano.

Para isso, inicia fazendo uma retrospectiva histórica da evolução do conceito de "tipo" na arquitetura, de modo a identificar como o debate tipológico incorporou e tratou a dimensão urbana. $\mathrm{Na}$ segunda parte, relaciona as visôes de tipologia urbana aos estágios de desenvolvimento do capitalismo e às características das cidades modernas e pós-modernas.

Finalmente, conclui questionando os limites e as possibilidades do conceito de tipologia para o entendimento e a ação na cidade contemporânea. 


\section{CONCEITOS DE TIPOLOGIA E DE TIPO}

Tipologia é, antes da mais nada, o estudo dos tipos. É a disciplina que se ocupa da discussão, classificação e fundamentação dos "tipos” (GREGOTTI, 1975).

O termo "tipo" deriva do grego túpos, usado para designar o meio concreto destinado à reprodução de um dado objeto. Assim sendo, a ideia de tipo surgiu relacionada à noção de uma espécie superior, profunda e original, da qual derivam as versóes dos diversos objetos (VIGIL, 2005).

Mas esse conceito de tipo não é único, nem é estático. Ao longo do tempo, o termo "tipo", quer na sua acepção geral, quer na sua aplicação à arquitetura e ao urbanismo, tem assumido sentidos bastante diferentes.

No século XVIII, a partir do Iluminismo, a palavra "tipo" passou a ser aplicada para expressar a essência de um conjunto de objetos, e seu conceito serviu de base para a classificação sistemática de diversas coisas, como plantas, animais e minerais. Datam dessa época as primeiras tentativas sistemáticas de conceituar e de construir tipologias arquitetônicas.

É de Quatremère de Quincy um dos conceitos de “tipo” mais antigos, discutidos e citados na literatura e na arquitetura. Quincy entendia o "tipo" como uma formulação abstrata, como um princípio. Além disso, dissociava a noção de "tipo" da ideia de modelo, ou seja, de objeto que se reproduz mecanicamente.

O tipo náo representa tanto a imagem de uma coisa que tenha que copiar-se e imitar-se perfeitamente, senão a ideia de um elemento que deve servir de regra ao modelo [...] $\mathrm{O}$ modelo [...] é um objeto que deve se repetir tal qual é; o tipo, ao contrário, é um objeto de acordo com o qual cada um pode conceber obras que náo se assemelhavam em absoluto entre si. (QUATREMÈRE DE QUINCY, [1823] apud ROSSI, 1995, p. 25-26).

Para Quatremère de Quincy (1977), cada solução de abrigo decorria de uma necessidade social e de hábitos de conduta, ou seja, havia uma conexão entre padróes sociais e características arquitetônicas. De acordo com Lavin (1992 apud NASCIMENTO, 2008), Quincy identificou três “tipos” primitivos fundamentais: a caverna, usada pelas sociedades nômades e caçadoras; a tenda, utilizada pelos coletores; e as cabanas fixas, características das sociedades sedentárias. Todos os demais edifícios tinham nesses três tipos suas matrizes tipológicas mais antigas.

Vidler (2006) mostrou que subjacente a esta visão de "tipo" estava uma crença de que existe uma ordem racional na natureza, que a arquitetura primitiva expressa essa ordem e, como tal, as formas primárias da geometria nelas utilizadas são preferíveis para a combinação dos elementos tipológicos.

Em outra linha analítica, mais relacionada ao ensino da prática da arquitetura, tem-se a classificação de edifícios e monumentos realizada por Jean-Nicolas-Louis Durand, em 1802. Movido pelo desejo de tornar o exercício do projeto do edifício uma atividade prática, racional e econômica, Durand construiu uma teoria dos tipos levando em conta aspectos geométricos da forma e desconsiderando questôes funcionais, ambientais, culturais e tecnológicas.

Para ele, a concepção do todo arquitetônico se dava mediante a combinação de seus elementos constitutivos. A partir dessa perspectiva, catalogou os principais elementos construtivos da arquitetura (pilares, escadas, halls, etc.), desenvolveu com- 
binaçôes, simplificou, esquematizou, reduziu e decompôs as formas da obra arquitetônica em "tipos", ressaltando suas propriedades geométricas e compositivas.

A versatilidade da noção de "tipo" de Durand permitiu a sua utilização tanto pelos arquitetos revivalistas quanto pelos racionalistas, o que fez com que acabasse funcionando como uma espécie de intermediário entre a Escola Politécnica de Paris, onde foi professor de 1795 a 1830, e as vanguardas da Escola de Belas Artes. Contudo, como reclama Édson Mafuz (1995 apud STRÖHER, 2001), faltou à tipologia de Durand, segundo seus críticos, um princípio que fosse capaz de estruturar o conjunto de elementos arquitetônicos decompostos, ou seja, um conceito central que articulasse as partes.

Desde entáo a noção de "tipo" em arquitetura tem oscilado entre estes dois polos básicos: de um lado, a ideia de um princípio ideal ou original, de natureza conceitual e estrutural, gerador das formas; e, de outro lado, a ideia de objeto material reprodutível, serializado, capaz de acelerar a reproduçâo à escala industrial. A primeira vinculada a uma teoria analítica que procura compreender a essência da arquitetura, e a segunda a um método prescritivo direcionado, sobretudo, a apoiar a prática do projeto.

Durante o movimento moderno, foi a visão do "tipo" como modelo reprodutível que ganhou força, visto que mostrou ser a mais útil e compatível com a necessidade de viabilizar, através do processo de racionalização, industrialização e reprodução arquitetônica, sobretudo da habitação, o processo de acumulação requerido pelo estágio em que se encontrava o desenvolvimento capitalista.

A lógica da máquina passou a determinar e a reger o conceito hegemônico de "tipo" enquanto objeto reproduzível. A arquitetura passou a ser vista como um produto a ser produzido em série para atender a demanda de um homem "tipo", ao mesmo tempo em que foi inserida em uma máquina maior - a cidade. A tipologia arquitetônica e urbanística, nesse contexto, foi determinada a partir de uma utopia social de igualdade, fundada na ideologia do progresso tecnológico (VIDLER, 2006; HARVEY, 1993).

A ideia do indivíduo-tipo (atemporal e a-espacial), dotado de necessidades-tipo (cientificamente dedutíveis), alimentou a busca por uma ordem espacial urbana-tipo (CHOAY, 1965). Os "tipos" urbanos de cidade total emergiram, então, não como resultados de uma reflexão teórica sobre a tipologia urbana mas meramente com o caráter propositivo; como utopias espaciais fundadas em utopias sociais totalmente desvinculadas de realidades socioeconômicas, geográficas, espaciais e culturais concretas (HARVEY, 2006).

Exemplos de propostas de "tipos" de cidades que já vinham se desenvolvendo desde o Renascimento, ainda que de forma tímida, multiplicam-se, a exemplo do Falanstério de Fourrier, passando pelas propostas de cidade-jardim de Ebnezer Howard, de cidade industrial de Tony Garnier, de cidade linear de Soria y Mata, da Brodacre City de Frank Lloyd Wright, até chegar às cidades que seguem os princípios da Carta de Atenas, como as propostas de Le Corbusier, e às inúmeras experiências de cidades novas que se espalham no mundo todo, tendo muitas delas servido de base para a construção e reconstrução de cidades nos Pós-Guerras.

A partir da segunda metade do século XX, o debate sobre os "tipos" foi retomado junto às críticas à arquitetura e ao urbanismo modernos, estes acusados de terem resultado na destruição de formas tradicionais preexistentes, na homogeneização dos espaços, no abandono da dimensão cultural, na desconsideração das especificidades locais e na falência das utopias espaciais urbanas. 
$\mathrm{Na}$ procura por uma alternativa ao movimento moderno, e na busca por resgatar a continuidade com a história, vista como necessária para a legibilidade da arquitetura no interior de uma cultura (NESBITT, 2006), a ideia de "tipo" foi retomada por arquitetos e pensadores italianos, franceses e, mais tarde, norte-americanos.

Nesse processo, os arquitetos italianos tiveram papel fundamental, pois começaram a utilizar os "tipos" arquitetônicos dos edifícios para pensar a cidade (NOBRE, 1993). Dentre os estudos mais relevantes destacaram-se os de Saverio Muratori; Gianfranco Caniggia e Gian Luiggi Maffei; Aldo Rossi; e de Giulio Carlo Argan.

Como mostra Nascimento (2008), Muratori considerava que os edifícios eram os componentes fundamentais da cidade. Com base nisso, estabeleceu um método descritivo e historiográfico para fazer a leitura da cidade a partir dos tipos de arquitetura dos edifícios. A tipologia edilizia, que foi inicialmente concebida para entender as cidades históricas italianas, procurou, então, identificar as características tectônicas que se mantinham ou que se alteravam nas diversas partes do edifício ao longo da história. Para construir a tipologia, o método de Muratori trabalhava com diversos pares constituídos por opostos, tais como elemento portante $\mathrm{x}$ elemento portado e edificação de base (residência) x edificação especializada (uso diferente do residencial). Com o tempo, o método de Muratori passou a ser utilizado para analisar, também, edifícios contemporâneos.

Para Caniggia e Maffei, a tipologia é "um conjunto orgânico de conhecimentos que se desenvolve a partir do fazer arquitetônico e se consolida na história, [sendo os "tipos"] passíveis de serem concretizados nas formas arquitetônicas" (NASCIMENTO, 2008, p. 29). Assim compreendendo a noção de "tipo", Caniggia e Maffei exploraram os elementos arquitetônicos identificados em estudos que adotaram o método de Muratori e, com a finalidade de auxiliar no processo projetivo, organizaram um manual de "tipos" de edifícios que foi amplamente utilizado em cursos de arquitetura.

Aldo Rossi (1995), amplamente influenciado pelo estruturalismo levistraussiano, utilizou a noção de "tipo" para analisar a relação entre edifício e cidade. Para ele, o "tipo" é a própria ideia, é o princípio da arquitetura e da cidade. Assim sendo, Rossi (1995), citando Quatremère de Quincy, entendeu o "tipo" como o enunciado lógico que precedia a forma e que a constituía. Para ele, o "tipo" não se confundia com a forma, "mesmo sendo todas formas redutíveis a tipos" (ROSSI,1995, p. 27); o "tipo" era a constante que pode ser encontrada na arquitetura dos edifícios e em todos os fatos urbanos.

Não obstante, quando passou a discutir a teoria dos fatos urbanos em Arquitetura da Cidade, sua obra mais importante, Rossi (1995), ao invés de buscar encontrar o princípio lógico fundante da forma urbana, apenas dividiu a cidade em área-residência (definidas por critérios de homogeneidade) e elementos primários (destacando os monumentos), e propôs que, a partir da análise comparativa desses segmentos, os "tipos" fossem identificados. Nesse momento, a opção tipológica de Rossi se afastou tanto da visão metafísica de Quincy quanto do estruturalismo de Saussure e Levis Strauss, aproximando-se mais das categorias criadas por geógrafos, como Tricart, Poète e Lavedan, que privilegiavam a forma física, material.

Entretanto, o debate sobre o conceito, a importância e a natureza dos "tipos" na arquitetura não se limitou às análises que relacionavam "tipos" edilícios à morfologia urbana.

A possibilidade de, com base em "tipos", criar novas formas e produzir obras de arte foi, por exemplo, a preocupação de Argan (2006), expressa no artigo in- 
titulado Sobre a tipologia na Arquitetura, publicado em 1967, e em outras obras. Para esse autor,

No processo de comparação e justaposição de formas individuais para determinar o “tipo", são eliminadas as características de cada prédio, permanecendo apenas aquelas que são comuns a todas as unidades da série. Portanto o "tipo" se constitui pela redução de um complexo de variantes formais a uma forma básica comum. Se o "tipo" se origina desse processo de regressão, náo se pode tomar a forma original como análoga a uma coisa tão neutra quanto uma grade estrutural. A forma base deve ser entendida como a estrutura interior de uma forma ou como princípio que contém a possibilidade de infinitas variaçôes formais e modificaçoes estruturais do "tipo" em si. (ARGAN, 2006, p. 270).

Para Argan (2006), os "tipos" se formam e são transmitidos pelo pensamento e pelas práticas da arquitetura. Nesse processo, é possível a criação de novos "tipos". Isso pode ocorrer tanto como resposta a transformaçôes socioculturais e tecnológicas, como mediante obras individuais.

Assim sendo, todo edifício pode ser reduzido a um "tipo", e não o podendo ser, isso significa que representa um novo modo organizado do espaço que precisa ser revelado, uma nova unidade significante, ou seja, que se constitui em um novo "tipo". Por isso Argan (2006) defende que os "tipos" merecem ser estudados, tanto do ponto de vista do "processo histórico da arquitetura" quanto do "processo ideativo e operativo dos arquitetos individualmente".

Argan (2006) sugere que critérios tipológicos podem ser funcionais, estruturais, formais etc. Ele classifica os "tipos" arquitetônicos básicos a partir de três grandes categorias: as configuraçóes gerais (planta central ou planta longitudinal); os elementos estruturais construtivos (coberturas planas ou cúpulas e sistemas em vigas ou arcos); e os elementos decorativos (ordens das colunas e elementos ornamentais). Para este autor, uma classificação em "tipos" assim constituída fornece um guia para o arquiteto conceber o edifício.

Ao questionar-se (e como), diante da rigidez ou da inércia dos "tipos" construídos historicamente, pode ocorrer o processo de criação artística, Argan responde afirmativamente, apontando a capacidade do artista de libertar-se do condicionamento de uma forma histórica determinada, ou seja, de negar o "tipo", mesmo que o tenha aceitado como ponto de partida.

Outro autor a discutir o papel da tipologia enquanto insumo à prática projetual foi Alan Colquhoun. Num artigo publicado em 1967, Colquhoun (2006) criticou o uso do determinismo biotécnico e da intuição nas metodologias de projeto modernistas. Mostrou que, na realidade, tal "intuição" se acha impregnada de soluçôes precedentes. Assim sendo, propôs recorrer ao estudo das tipologias como estratégia para reconhecer as transformações de soluçóes passadas e como instrumento relevante a ser utilizado no método de projeto.

Vittorio Gregotti (1975) também se preocupou em como construir tipologias. Nesse sentido, relacionou dois aspectos fundamentais na definiçáo tipológica da arquitetura: a organização estrutural e a organização funcional. Além disso, ressaltou que esses aspectos deveriam ser considerados para compor tanto "tipos comprovados" (existentes) quanto os "tipos ideais" (pensados).

Por destacar a dimensão funcional na constituição do "tipo", Gregotti (1975) 
identificou uma crise dos estudos tipológicos, atribuindo-a à evolução das tecnologias construtivas, à disseminação de edifícios multifuncionais, à necessidade de flexibilidade de uso e às dificuldades da arquitetura de transmitir mensagens eficientes. Para ele, a transformação e o movimento são os novos parâmetros da tipologia, e os organismos arquitetônicos tendem a criar uma nova unidade formal entre "tipo" e "organismo".

Outros autores poderiam ser evocados para aprofundar o debate sobre o "tipo" na arquitetura, mas, o que importa, para os fins de construção do argumento deste artigo, é destacar que, com a crítica ao movimento moderno, emergiu o que Vidler (2006) denominou de "terceira tipologia", cujo foco de interesse passou a ser a cidade. Não que essa tipologia tivesse se voltado para entender as cidades e procurar classificá-las ou desenhá-las, ressalte-se. Ao invés disso, a cidade foi vista apenas como portadora de exemplares arquitetônicos, como meio que oferecia aos arquitetos o material para a identificação e classificação das formas arquitetônicas, estas tratadas menos como "tipos" conceituais e mais como "tipos" físicos, materiais e, sobretudo, formais.

\section{A TIPOLOGIA E AS CIDADES MODERNA E PÓS-MODERNA}

Colocadas no âmbito da morfologia urbana, duas abordagens sobre tipologia urbana têm sido dominantes nos estudos desenvolvidos pelos arquitetos e urbanistas desde o século XIX: a que considera a cidade a partir de seu desenho total, ou seja, enquanto unidade e totalidade; e a que considera a cidade a partir de seus fragmentos, ou seja, de suas partes constitutivas. A primeira dessas abordagens foi dominante no modernismo, já a segunda no pós-modernismo, entendendo-se por pós-modernismo a reação e/ou o afastamento do modernismo.

David Harvey, ao tentar compreender os conceitos de modernismo e pós-modernismo, lança mão de uma citação de Precis para afirmar que:

10 pós-modernismo, então, viria decretar o fim das metanarrativas, da razão manipuladora e do fetiche da totalidade propalados pelo modernismo, retomando o pluralismo e a heterogeneidade dos estilos de vida (EAGLETON, 1984 apud HARVEY, 1993).
'Geralmente percebido como positivista, tecnocêntrico, universal e racionalista, o modernismo tem sido identificado como a crença no progresso linear, nas verdades absolutas, no planejamento racional de ordens sociais ideais, e com a padronização do conhecimento e da produção'. O pós-moderno, em contraste, privilegia 'a heterogeneidade e a diferença como forças libertadoras do discurso cultural'. A fragmentação, a indeterminação e a intensa desconfiança de todos os discursos universais ou (para usar um termo favorito) 'totalizantes' são o marco do pensamento pós-moderno. (PRECIS, 1987 apud HARVEY, 1993, p. 19) 1 .

O modernismo tratou da cidade em sua totalidade espacial. Ao negar a cidade tradicional, impôs - baseado nas proposiçóes dos Congressos Internacionais de Arquitetura Moderna (CIAMs), em especial na Carta de Atenas - um "tipo ideal" de cidade, cuja síntese mais acabada se encontra na Ville Radieuse, de Le Corbusier. Esse "tipo" se caracteriza, dentre outros: pela rigidez do zoneamento das funçôes e da hierarquia viária; pela segregação de fluxos (veículos x pedestres); pela eliminação dos lotes individuais e a liberação do solo dos edifícios; e pela implantação de vastas áreas de bosques nos interstícios dos edifícios. 
Nesse contexto, o debate teórico sobre os "tipos" enfatizou as dimensôes funcionais e quantitativas da habitação-mínima, sendo esta considerada como a "célula básica”, cuja agregação geraria o edifício; estes gerariam a unidade de vizinhança; e estas, por sua vez, a própria cidade.

Com a crise do movimento moderno e a tomada de consciência da insuficiência do projeto utópico da cidade modernista para dar conta, quer seja das dimensóes sociais, econômicas e culturais das sociedades, quer seja para responder às necessidades individuais humanas (objetivas e subjetivas), emergiu a segunda abordagem de "tipo" na arquitetura e no urbanismo.

No âmbito da arquitetura, a tendência dominante foi a de abandonar a ideia abstrata de "tipo" e de procurar definir tipologias a partir de critérios de diferentes naturezas, sobretudo os formais. Na esfera urbana, a nova abordagem negou a possibilidade de apreensão da cidade em sua totalidade e impôs uma visão de cidade enquanto conjunto de fragmentos que se póem e superpóem no espaço, gerando e agregando múltiplas temporalidades e espacialidades.

Como mostrou Harvey (1993, p.69), no campo do urbanismo, o pós-modernismo rompeu com a ideia modernista:

[...] de que o planejamento e o desenvolvimento devem concentrar-se em planos urbanos de larga escala, de alcance metropolitano, tecnologicamente racionais e eficientes, sustentados por uma arquitetura absolutamente despojada [...]. O pós-modernismo cultiva, em vez disso, um conceito do tecido urbano como algo necessariamente fragmentado, um "palimpsesto" de formas passadas superpostas umas as outras e uma colagem de usos correntes, muitos dos quais podem ser efêmeros.

Nesse contexto, o conceito de tipologia, que havia sido teoricamente forjado no âmbito da arquitetura do edifício, incorpora a dimensão urbana, procurando, na diversidade dos tecidos e padróes arquitetônicos passados, estruturas e modelos capazes de explicar e, sobretudo, subsidiar projetos pontuais de intervenção na cidade contemporânea.

De uma maneira geral, a cidade deixou de ser vista como uma totalidade e passou a ser encarada como a soma de fragmentos. Abandonou-se o zonning da cidade ideal total modernista, considerado antiecológico por Leon Krier, em favor de uma espécie de zonning pós-moderno, baseado em fragmentos morfológicos, mais ou menos homogêneos.

Se, no modernismo, as zonas das cidades utópicas se viam esvaziadas de seus conteúdos socioculturais e temporais, agora, as zonas pós-modernas se veem ilhadas e desarticuladas de seu contexto urbano mais global.

Rossi $(1995,1977)$ é um exemplo disso. Sua Teoria dos Fatos Urbanos destacava a importância de estudos de tipologia urbana e defendia a permanência de fragmentos de relevância histórica, face às ameaças de tabula rasa modernista. Mas, ao mesmo tempo, sua prática arquitetônica inseria, em fragmentos do tecido urbano, obras que se constituem em verdadeiras alegorias formais, mesclando elementos clássicos com elementos modernos, esvaziando os "tipos" arquitetônicos de seus conteúdos históricos.

Outro exemplo dessa postura é encontrado em Colin Rowe e Fred Koetter (1981). Usando a técnica de figura-fundo, após comparar fragmentos da cidade moderna e da cidade tradicional e de fazer uma analogia com a ágora e o fórum romano, 
esses autores defendem a cidade-colagem como a única alternativa capaz de permitir a convivência entre utopia e tradição, de incorporar uma visão não linear do tempo e de alimentar o movimento, a mudança e a ação na história.

Alguns historiadores da cidade também foram vítimas dessa armadilha. Estes, que implicitamente vinham utilizando o conceito de tipologia urbana para caracterizar e classificar as formas das cidades produzidas em diferentes momentos e culturas, quando passaram a tratar da cidade contemporânea, abandonaram seus métodos de abordagem e passaram a tratar do fragmento ou apenas de facetas muito limitadas dos problemas gerais da urbanização, já que não conseguiam mais articular um discurso da forma total, nem lidar com as dimensóes e a diversidade de arranjos espaciais existentes na cidade contemporânea. Exemplos disso são abundantes na literatura urbana.

As macroteorias e os instrumentais teórico-metodológicos que haviam permitido a esses estudiosos definir "tipos" ou modelos conceituais das cidades antigas, medievais, renascentistas, e mesmo modernas, não eram mais eficientes e aceitos, nem se mostravam adequados para tratar da cidade contemporânea. Assim, a noção de "tipos" de cidades também se esfacelou. A tipologia urbana se tornou a tipologia dos fragmentos do espaço urbano, fragmentos esses cada vez mais desarticulados entre si, de menor dimensão e menos representativos da totalidade urbana.

Os próprios trabalhos de estudiosos da morfologia urbana parecem ter embarcado nessa viagem. Mesmo Panerai (2006) - que, baseado em Muratori (1959 apud PANERAI, 2006), reclamou a necessidade de situar o "tipo" no tecido e o tecido na estrutura urbana - encontrou dificuldades em lidar com a cidade total.

Para Panerai (2006), algumas convençôes espaciais se estabelecem entre projetistas, construtores, mestres de obras e clientes de dado momento histórico e em um determinado lugar. Tais acordos determinam relaçôes de correspondências entre disposiçóes espaciais, ornamentos e usos do edifício, e estas definem os "tipos", alguns estáveis, consagrados pela história, mesmo quando sujeitos às reinterpretaçôes locais.

Vale ressaltar que a ideia da cidade-fragmento reforçou, amplamente, a crise do planejamento urbano compreensivo, e foi por ela alimentada. A ideologia de que é impossível desenhar e regular a forma da cidade total invadiu o mundo técnico e acadêmico, que passou a advogar ou a legitimar, com seu discurso, as intervençóes neoliberais pontuais e localizadas na cidade, quando não o próprio laissez faire.

Como mostra Bernardo Secchi (2006, p. 88), nesse contexto, a cidade contemporânea aparece "como um confuso amálgama de fragmentos heterogêneos, no qual não é possível reconhecer nenhuma regra de ordem, nenhum princípio de racionalidade que a faça inteligível”. Este autor, citando Henry Miller, lembra, contudo, que "confusão é uma palavra inventada para indicar uma ordem que não se compreende". (MILLER, s/d apud SECCHI, 2006, p. 88).

A cidade da acumulação flexível, do neoliberalismo, da desregulamentação e do Estado empreendedor encontrou, assim, o modelo de tratamento e de intervenção urbana mais flexível e, portanto, mais adequado às novas necessidades do desenvolvimento capitalista. Nesse quadro, parece não haver espaço para pensar a tipologia urbana além da tipologia formal do fragmento. 


\section{À GUISA DE CONCLUSÃO}

O presente trabalho procurou investigar como o conceito de "tipo", emanado do debate da arquitetura do edifício, tem sido pensado e utilizado na escala urbana.

A partir de uma breve retrospectiva histórica do desenvolvimento do conceito e dos estudos de tipologia arquitetônica, procurou-se mostrar que, embora em termos teóricos o conceito de tipologia urbana seja pouco discutido e trabalhado, na prática e no discurso, de um modo ou de outro, ele tem aparecido.

Revelou, também, que a derivação da noção de tipologia da arquitetura do edifício para a arquitetura urbana reflete o papel da cidade em cada estágio do desenvolvimento do capitalismo.

Essa derivação resultou na transição de uma visão de "tipos" de cidades, que considera o espaço urbano como um todo, dominante no modernismo, para uma visão de "tipos" na cidade, prevalente no contexto pós-moderno.

A dificuldade de apreender a cidade contemporânea de maneira abrangente, quer seja considerando sua forma física, quer seja levando em conta as leis gerais que a estruturam e lhe dão forma, é atribuída, de um lado, ao crescente tamanho, complexidade e heterogeneidade da cidade contemporânea; e, de outro lado, à ausência de interesses convergentes em classificaçóes tipológicas globalizantes.

Num contexto de crise do Estado intervencionista, em que a ação sobre a cidade se faz de forma pontual e de modo a atender a interesses pulverizados e localizados, enfim, na fase do capitalismo caracterizada pela flexibilidade, mobilidade, compressão espaço-tempo, desregulamentação e busca incessante por inovação, sobra pouco espaço para o debate e o resgate de visóes totalizantes.

Diante desse quadro, até que ponto, então, faz sentido pensar e classificar as cidades em "tipos"?

Classificar é um procedimento básico e natural da cognição humana que consiste em agrupar objetos ou fenômenos em categorias, segundo critérios preestabelecidos. Os sistemas de classificação procuram trazer objetos e fenômenos desconhecidos ou complexos para categorias passíveis de serem manipuladas, oferecendo informaçóes que subsidiem a ação. As classificaçôes organizam o pensamento, facilitam a formulação de hipóteses de investigação e, em alguns casos, até subsidiam previsóes. Elas também podem ser úteis para exprimir a organização do espaço urbano e para subsidiar a definiçáo de políticas e açóes de ordenamento espacial.

À parte do debate tipológico, as cidades são, em todo momento, classificadas com base em diferentes critérios (sincrônicos ou diacrônicos) de natureza demográfica, socioeconômicos, geográficos, morfológicos, funcionais, estruturais, etc.

Embora parte dessas classificaçóes resulte mais de raciocínio científico do que de um esforço classificatório, todas são muito artificiais e reducionistas, pois são fundadas num pequeno número de critérios, normalmente restritos a um campo disciplinar específico. Como consequência, originam classificaçôes de cidades extremamente heterogêneas e frágeis, se vistas sobre outro conjunto de aspectos.

Fazer de conta que essas classificaçôes não são realizadas e não são necessárias para o entendimento e a ação sobre a cidade não resolve um problema maior, que é o do enfrentamento das dificuldades de compreensão da cidade contemporânea numa perspectiva que supere a ideia de que ela se constitui mediante a mera soma das suas partes. 
Helena Lucia Zagury Tourinho é arquiteta e urbanista e mestre em Planejamento do Desenvolvimento pela Universidade Federal do Pará (UFPA); doutora em Desenvolvimento Urbano pela Universidade Federal de Pernambuco (UFPE); professora e pesquisadora do Programa de Mestrado em Desenvolvimento e Meio Ambiente Urbano e do curso de graduação em Arquitetura e Urbanismo na Universidade da Amazônia (UNAMA), Brasil.E-mail: helenazt@uol. com.br

Artigo recebido em dezembro de 2013 e aprovado para publicação em março de 2014.

A apreensão do espaço da cidade contemporânea requer um esforço de resgate da totalidade, totalidade que deve ser entendida não só como a extensão para contemplar a dimensáo total da cidade mas também que considere o conjunto de critérios classificatórios utilizados para construir os "tipos".

Bernardo Secchi (2006, p. 73) mostra que "a escritura da cidade nota por nota" colocou problemas relevantes concernentes às relaçôes "entre o elemento singular e o todo, entre o uno e o múltiplo". Para ele, desconsiderar a dimensão da totalidade urbana é tâo danoso quanto deixar de reconhecer as diversidades de suas partes singulares. Como atenta Secchi (2006, p. 167): "Os fragmentos da cidade contemporânea são os materiais de um sistema aberto. Suscetíveis à repetição, à conexão e composição, eles propôem-se ao estudo e à experimentação enquanto materiais urbanos."

Esse parece ser um tema que merece ser colocado na agenda dos urbanistas e estudiosos da cidade.

\section{REFERÊNCIAS BIBLIOGRÁFICAS}

ARGAN, G. C. Sobre a tipologia em arquitetura. In: NESBITT, K.(Org.). Uma nova agenda para a arquitetura: antologia teórica (1965-1995). São Paulo: Cosac Naify, 2006 [1963], p. 268-273.

CHOAY, F. O urbanismo. São Paulo: Ed. Perspectiva, 1965.

COLQUHOUN, A. Tipologia e metodologia de projeto. In: NESBITT, K. (Org.). Uma nova agenda para a arquitetura: antologia teórica (1965-1995). São Paulo: Cosac Naify, 2006 [1967], p. 274-283.

GREGOTTI, V. Território da arquitetura. São Paulo: Perspectiva, 1975.

HARVEY, D. A condição pós-moderna. Sáo Paulo: Loyola, 1993.

Os espaços de utopia. In: Espaços de esperança. 2.ed., São Paulo: Loyola, 2006, p. 181-238.

NASCIMENTO, C. F. B. Recorrências e particularidades entre edifícios: os conceitos de tipo e tipologia. In: Até os limites do tipo: emergência, adequaçáo e permanência das propriedades sócio-espaciais dos edifícios de re-formação. 2008. 188 f. Dissertação (Mestrado em Desenvolvimento Urbano) - Centro de Artes e Comunicaçáo, Universidade Federal de Pernambuco, 2008. p. 20-38.

NESBITT, K. (Org.). Uma nova agenda para a arquitetura: antologia teórica (1965-1995). São Paulo: Cosac Naify, 2006 [1967].

NOBRE, E. A. C. Os tipos na arquitetura e no urbanismo. 1993. Disponível em:<www.usp.br/ fau/docentes/depprojeto/e_nobre/tipos_arq_urb.pdf>. Acesso em: 27 nov. 2007.

PANERAI, P. Tipologias. In:___ Análise urbana. Brasília: Ed. UnB, 2006. p. 109-138. ROSSI, A. A arquitetura da cidade. São Paulo: Martins Fontes, 1995.

Tipologia, manualística y arquitectura. In: Para uma arquitectura de tendência: escritos 1956-1972. Barcelona: Gustavo Gili, 1977 [1966]. p. 184-192. ROWE, C.; KOETTER, F. Ciudad collage. Barcelona: Gustavo Gili, 1981. SECCHI, B. Primeira lição de urbanismo. São Paulo: Perspectiva, 2006. STRÖHER, R. A. Quatremère de Quincy e Jean-Nicolas-Louis Durand: algumas consideraçôes sobre a interpretação do conceito de tipo em arquitetura. In. STRÖHER, E. R. (Org.). O tipo na arquitetura: da teoria ao projeto. São Leopoldo: Ed. Unisinos, 2001. p. 9-24. QUATREMÈRE DE QUINCY, A. C. Type. Opposition. v. 8, p. 617-620, 1977. VIDLER, A. A terceira tipologia. In: NESBITT, K. (Org.). Uma nova agenda para a arquitetura: antologia teórica (1965-1995). São Paulo: Cosac Naify, 2006 [1976]. p. 285-289. 
VIGIL, P. A. Análisis tipológico. In: (Coord.). Análisis formal del espacio urbano: aspectos teóricos. Lima: Instituto de Investigación de la Facultad de Arquitectura Urbanismo y Artes, 2005. p. 135-147.

A B S T R A C T : This paper discusses the development and application of the concept of typology in the analysis of modern and postmodern space. It shows that the derivation of the notion of a typology of the built environment has been insufficient for understanding and classifying contemporary cities, since it reduces them to unlinked sets of fragments in space. After questioning the importance and usefulness of such a typological category and the need for one in order to apprehend the urban form in the current stage of the development of capitalism and cities, the article concludes by indicating the need to rethink the concept of urban typology in order to salvage the vision of urban wholeness without losing sight of the diversities and complexity of current intra-urban space.

K E Y W O R D S : urban typology; architectural typology; urban form; modernism; postmodernism. 